\title{
Physical inactivity and metabolic factors as predictors of weight gain.
}

Citation for published version (APA):

Saris, W. H. M. (1996). Physical inactivity and metabolic factors as predictors of weight gain. Nutrition Reviews, 54(4), 110-115.

http://www.ncbi.nlm.nih.gov/entrez/query.fcgi?cmd=Retrieve\&db=pubmed\&dopt=Abstract\&list_uids=8700 437

Document status and date:

Published: 01/01/1996

Document Version:

Publisher's PDF, also known as Version of record

\section{Please check the document version of this publication:}

- A submitted manuscript is the version of the article upon submission and before peer-review. There can be important differences between the submitted version and the official published version of record.

People interested in the research are advised to contact the author for the final version of the publication, or visit the DOI to the publisher's website.

- The final author version and the galley proof are versions of the publication after peer review.

- The final published version features the final layout of the paper including the volume, issue and page numbers.

Link to publication

\footnotetext{
General rights rights.

- You may freely distribute the URL identifying the publication in the public portal. please follow below link for the End User Agreement:

www.umlib.nl/taverne-license

Take down policy

If you believe that this document breaches copyright please contact us at:

repository@maastrichtuniversity.nl

providing details and we will investigate your claim.
}

Copyright and moral rights for the publications made accessible in the public portal are retained by the authors and/or other copyright owners and it is a condition of accessing publications that users recognise and abide by the legal requirements associated with these

- Users may download and print one copy of any publication from the public portal for the purpose of private study or research.

- You may not further distribute the material or use it for any profit-making activity or commercial gain

If the publication is distributed under the terms of Article $25 \mathrm{fa}$ of the Dutch Copyright Act, indicated by the "Taverne" license above, 


\title{
Physical Inactivity and Metabolic Factors as Predictors of Weight Gain
}

\author{
Wim H.M. Saris \\ University of Maastricht
}

\section{Introduction}

Obesity, defined as an excess of body fat relative to lean body mass, is the consequence of a chronic imbalance between energy intake and energy expenditure. In spite of this well defined etiology of the disease, it is not yet clearly established whether the main abnormality responsible for the increase in body fatness is chronic excess of energy intake, a defect in energy expenditure, or perhaps a combination of both. Despite the fact that everyone agrees energy intake exceeds expenditure during weight gain, detailed information whether energy expenditure rises insufficiently to match the fluctuations in intake or vice versa is lacking.

The major difficulty in all studies addressing this topic is the necessity to measure small differences between energy intake and components of energy expenditure, such as resting metabolic rate (RMR), diet-induced thermogenesis, or exercise-induced energy expenditure. If in an adult man energy intake exceeds energy expenditure by $4 \%$ each day, a daily imbalance of approximately $100 \mathrm{kcal}$ will result, which corresponds with a doubling of the body weight in 15 years if no precise adaptive mechanisms are active to counteract this relatively small energy imbalance on a daily basis.

\section{Energetic Aspects of Body Weight Regulation}

The above mentioned illustrates two important aspects of the research on body weight regulation.

Firstly, on a daily or weekly basis the absolute difference in calories is very small, which will cause weight gain in the long term. In the classic seven-country study, weight gain in the Dutch cohort of Zutphen men was $7 \mathrm{~kg}$ over a period of 15 years. The energy balance differences account for less than $1 \%$ in the RMR, which is already at the limits of current methods to assess significant differences between weight gainers and non-weight gainers in the Zutphen study.

Secondly, increases or decreases in body weight in response to an energy imbalance are accompanied by changes in body composition and in maintenance energy requirements, which modify the subsequent pattern of weight gain progressively.
Recently Weinsier et al. (1993) predicted the theoretical effect of a persistent reduction in energy expenditure on long term weight gain, assuming no adaptation in energy intake. They used previously reported data on body composition and RMR in women and the energy costs of tissue deposition. The analysis with mathematical models indicated remarkable differences in the outcome of a reduced level of energy expenditure in lean and obese women, as is shown in Table 1. With increasing degree of obesity, RMR rises more slowly due to a lower ratio between fat-free mass (FFM) and fat mass. Proportionately less metabolically active tissue will ultimately lead to greater weight gain in the obese compared with the lean individual. Due to the greater energy content of adipose tissue, the time course for reaching a new equilibrium will be longer.

Table 1. Predicted effect of a $50 \mathrm{kcal} / \mathrm{d}$ or $200 \mathrm{kcal} / \mathrm{d}$ reduction in energy expenditure on the amount, composition (\% fat mass [FM]), and time course ( $y$ ) of weight gain among lean, normal, and obese women

\begin{tabular}{lccc}
\hline $\begin{array}{l}\text { Reduced } \\
\text { energy expenditure }\end{array}$ & $\begin{array}{c}\text { Lean } \\
(\mathbf{5 0 k g})\end{array}$ & $\begin{array}{c}\text { Normal } \\
(\mathbf{6 5} \mathbf{k g})\end{array}$ & $\begin{array}{c}\text { Obese } \\
(\mathbf{1 0 0} \mathbf{k g})\end{array}$ \\
\hline $50 \mathrm{kcal} / \mathrm{d}$ & $+3.1(\mathrm{~kg})$ & $+3.6(\mathrm{~kg})$ & $+4.6(\mathrm{~kg})$ \\
& $54 \%(\mathrm{FM})$ & $67 \%(\mathrm{FM})$ & $82 \%(\mathrm{FM})$ \\
& $4.5(\mathrm{y})$ & $6.1(\mathrm{y})$ & $9.1(\mathrm{y})$ \\
& $+13.4(\mathrm{~kg})$ & $+15.5(\mathrm{~kg})$ & $+19.4(\mathrm{~kg})$ \\
& $59 \%(\mathrm{FM})$ & $70 \%(\mathrm{FM})$ & $84 \%(\mathrm{FM})$ \\
& $5.3(\mathrm{y})$ & $6.9(\mathrm{y})$ & $9.8(\mathrm{y})$ \\
\hline
\end{tabular}

Adapted from Weinsier et al. (1993).

Based on these calculations, which assume there are no adaptations in energy intake or biological changes in thermogenic capacity and daily physical activity, it takes about 5 years for the lean individual and 10 years for the obese woman to reach a steady state situation. This type of weight gain simulation study gives better insight into the physics of energy balance or imbalance in light of the first and second law of thermodynamics and practical outcome in daily life.

Too often weight gain is attributed to mechanisms that violate the basic principles of physics. However, to keep 
weight within normal ranges, metabolism will up- or downregulate energy expenditure. At the same time, human metabolism is the result of genetic selection in the struggle for life and survival of the fittest. The ability to lay down fat rapidly when there is an abundance of food to survive in periods when food becomes scarce is merely part of our genetic background. The dramatic changes in lifestyle and food availability during the last century, however, did not change our metabolic drive to secure energy reserves. The classic Minnesota semistarvation study performed by Ancel Keys et al. (1950) shows this metabolic drive for energy conservation in detail: 24 weeks of starvation resulted in a $25 \%$ loss of body weight. In absolute terms, RMR decreased by nearly $40 \%$. This was partly due to loss of metabolically active tissue such as muscle. However, the metabolic rate per unit of active tissue also decreased by about 15\%. Although the Minnesota study did not measure daily physical activity, based on the energy balance calculation it seems certain that energy was also saved by reduced levels of activity.

Recently Leibel et al. (1995) published a study on the effects of metabolic drive from aitered body weight. Lean and obese individuals were over- and underfed to change body weight to $+10 \%$ above initial body weight and $-10 \%$ and in the obese also to $-20 \%$ initial body weight. The investigators measured at different levels of stable body weight resting and nonresting energy expenditure by use of the precise doubly labeled water technique. The results clearly showed that the human body has a powerful mechanism to adapt metabolism and behavior to burn excess calories or to shut down energy turnover to save energy in a situation of food shortage.

As in the Minnesota study, RMR corrected for changes in body weight, and body composition decreased with about $12 \%$ in the $-10 \%$ initial body weight status. In contrast to the Minnesota study, further decline of body weight to $-20 \%$ initial body weight did not lead to additional energy efficiency in $(-13 \%)$ RMR in the study of Leibel et al. As expected, RMR was higher at the $+10 \%$ initial body weight steady state level, demonstrating the metabolic drive to burn extra calories to reduce body weight to the initial level. No differences could be detected between lean and obese groups.

Of greater interest was the change in nonresting energy expenditure, as shown in Table 2 in the $+10 \%,-10 \%$, and $-20 \%$ levels. The adaptation was remarkable. In the $+10 \%$ level, about $60 \%$ ex tra energy corrected for changes in body weight, and body composition was spent.

Since no differences could be measured in diet-induced thermogenesis at all body weight levels, the adaptation must be attributed to an increase in the energy expenditure due to exercise. Also, in the below initial body weight levels $(-10 \%$ and $-20 \%)$, adaptation met expectations for energy saving with decreasing body weight levels. Differences in energy needed for weight-bearing activities can only account for a small part of the observed differences, as was shown by Weigle and Brunzell (1990).
Therefore, although information is lacking, metabolic adaptations such as mechanical efficiency during exercise or changes in behavior such as decreased or increased levels of activity (e.g., moving around) must occur. This makes nonresting energy expenditure a very important component in the regular capacity to keep body weight within specific limits.

Table 2. Observed minus predicted total energy expenditure (EE), resting $E E$, and nonresting $E E$ (TEE-RMR) (kcal/ d) after a change in weight compared with initial weight (\% change in $\mathrm{kcal} / \mathrm{kg}$ FFM compared with initial weight)

\begin{tabular}{lccc}
\hline & $\begin{array}{c}\text { Total } \\
\text { EE }\end{array}$ & $\begin{array}{c}\text { Resting } \\
\text { EE }\end{array}$ & $\begin{array}{c}\text { Nonresting } \\
\text { EE }\end{array}$ \\
\hline Weight gain $+10 \%$ & 444 & +17 & +435 \\
& $(+16 \%)^{*}$ & $(+1 \%)^{*}$ & $(+58 \%)^{*}$ \\
Weight loss $-10 \%$ & -229 & -91 & -161 \\
& $(-15 \%)^{*}$ & $(-11 \%)^{*}$ & $(-19 \%)^{*}$ \\
Weight loss $-20 \%$ & -301 & -79 & -273 \\
& $(-25 \%)^{*}$ & $(-13 \%)^{*}$ & $(-42 \%)^{*}$ \\
\hline
\end{tabular}

"Significant compared with initial weight. Adapted from Leibel et al. (1995).

Changes in skeletal muscle may play a role in mediating the alterations in energy expenditure. Further detailed research on the role of skeletal muscle in energy balance is urgently needed.

\section{Components of Energy Expenditure and the Contribution of Daily Physical (In)Activity}

Total energy expenditure can be divided into three main components: resting metabolic rate, thermogenic response to food, and physical activity.

\section{Resting Metabolic Rate}

In the search for possible genetic mechanisms underlying intersubject variability in RMR, several aspects have been explored in the past decade. One interesting question is related to the impact of sex on energy turnover per unit of active cell mass. We, as well as Ravussin et al., found a lower RMR corrected for differences in lean body mass, fat mass, and age resulting in a 75 to $100 \mathrm{kcal} / \mathrm{d}$ difference. It is most likely that the differences can be attributed to the effect of sex hormones on energy turnover of active cell mass. So far no clear sex difference could be detected per unit of skeletal muscle mass in energy turnover or maximal power output that could be attributed to the observed RMR difference. Whether the level of physical activity is a determinant of RMR is still under debate. In general, one can say that women are less active. Especially at a younger age, this difference is striking (Saris et al. 1986). Whether this explains the observed sex effect on RMR is unknown. Some studies demonstrated a relationship between the level of physical fitness and RMR (Tremblay et al. 1986, Poehlman et al. 1988). Although there is general consensus that a higher level of physical activity coincides with better physical fitness, it is also 
clear that those with a genetically better predisposition to be fit can actually be very inactive before fitness levels are affected.

Several studies searched for ditferences in daily physical activity and the effect on RMIR. The results are controversial since one of the major problems is the measurement and definition of daily physical activity. A lower level of movement, for instance shorter walking distance during a game, does not automatically mean a lower energy turnover: In fact, moving around with a higher body mass implies higher energy cost. In the studies of Waxman and Stunkard (1980) and Saris et al. (1983), no differences in energy expenditure were found between obese and lean children after correcting for larger body mass. However, observation scores were significantly lower in the obese children. Furthermore, activity is difficult to measure accurately over longer periods of time without interfering with the daily routine (Saris 1986). This lack of precision has very possibly obscured the relationship between RMR and physical activity.

In a recent study by Westerterp et al. (1991) that used the doubly labeled water method (which is considered the gold standard technique to measure daily physical activity in sedentary and moderately active subjects), a positive relationship between energy expenditure and RMR was observed $\left(r^{2=.72 k}\right.$. An ideal study design to address this topic is a prospective training study in sedentary individuals. Poehlman (1989) hypothesized that RMR could be incrensed when the energy turnover rate is highly competitive with the maintenance of energy balance. In support of this hypothesis is the observation of Tremblay et al. (1988) showing a $6.6 \%$ drop in RMR in highly trained athletes who followed a 3-day detraining schedule. Only one of the prospective studies by Tremblay et al. (1986) showed a significant effect of training on RMR, with the time between the last exercise bout and the RMR measurement varying between 12 and 264 hours.

So far the evidence for a training effect on RMR is limited. Yet the mechanism by which exercise can modulate weight loss/gain is perhaps regulated by nutrient partitioning, which is partly influenced by the sympathetic nervous system. Also, resting skeletal muscle metabolism seems to be of importance for the entire body metabolism. It is estimated that around $40-50 \%$ of total energy expenditure is generated by the skeletal muscle (Astrup et al. 1985). Therefore, genetic alterations of skeletal muscle metabolism in trained or untrained conditions may be part of the thermoregulatory defect in relation to obesity. The impact of this skeletal muscle metabolism as a risk factor for weight gain will be discussed later.

From elegant studies in Pina Inclinns, who are very prone to become obese, it became clear that a low RMR is an important risk factor for weight gain. After only 4 years of follow-lip, the risk of gaining $10 \mathrm{~kg}$ was approximately eight times larger in those subjects who had the lowest RMR compared with those with the highest RMR (Ravussin et al. 1988). This demonstrates that, clue to its impact on total energy, even very small differences not detectable with today's methods for measuring RMR have major influence on weight balance.

\section{Thermogenic Effect of Feeding}

Dietary thermogenesis includes two components. The first is obligatory and related to the energy cost of digesting, absorbing, and processing or storing the nutrient. The second component represents the capacity to burn excess calories in the situation of excess energy intake. There is general consensus that the sympathetic nervous system plays a crucial role in this process. This is in contrast with the role of a possible impairment of diet-induced thermogenesis in the etiology of obesity. An enormous number of studies have addressed this issue. There is, however, conflicting evidence. Besides differences in the composition of test meals or the duration of measurements, it has become clear that the measurement of diet-induced thermogenesis itself has a large coefficient of variation (about $35 \%$ ), which can explain most of the conflicting results. Even under the conditions for which there is agreement regarding the role of an impaired thermogenic effect of food in the pathogenesis of obesity, indiviclual differences in diet-induced thermogenesis can only account for small differences in daily energy expenditure. This implies only a minimal weight gain.

\section{Daily Physical Activity}

The most attractive component of daily energy expenditure as a cause of obesity is physical inactivity. Athletes in most sports are lean, and increased body fatness is firequently seen in those who quit sports. Obese individuals are normally not physically active, and if they start a training program they lose body fat. The diflerence in physical activity between normal and overweight individuals has been examined in a plethora of studies, but the available data are by no means conclusive.

The studies are severely hampered by methodological problems and a lack of clarity about the definition of physical activity. Reduced activity may partly be balanced by increased energy cost of weight-bearing activities. In fact, moving around with a higher body mass implies a higher energy cost. This fact was demonstrated in a weight loss study in which, during the weight reducing regimen, each subject wore a vest with weights compensating for his or her weight loss. The decrease in energy expenditure during weight loss was only half that of the control subjects who did not compensate for their identical weight loss (Weigle and Brunzell 1990). Until the recent introduction of the doubly labeled water method, there has been no satisfactory method for assessing the impact of differences in daily physical activity on weight gain. No large differences were revealed after comparing obese and lean groups of children in the so-called physical activity factor; expressed as a multiple of ranges from 1.7 to 1.9 for dif- 
ferent groups of children or adolescents, with no clear tendency for lower values in more obese groups. It implies that inactivity is not the prime factor causing the positive energy balance. However, most studies in children and adults are cross-sectional and are limited to small numbers due to the high costs of using the doubly labeled water method. Recently, the first meta-analysis was published on the relationship between physical activity and body fatness based on doubly labeled water measurements (Schulz and Schoeller 1994). Stepwise multiple regression demonstrated that fat-free mass and age explain $65 \%$ of the variation in daily energy expenditure. Even more important was the strong negative relationship between body fatness and nonbasal energy expenditure divided by weight (Figure 1).

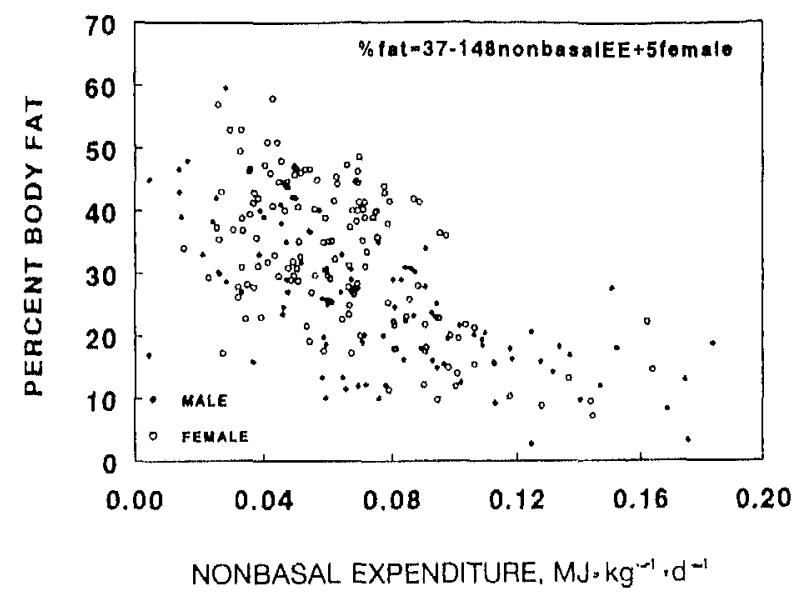

Figure 1. Relationship between body fatness and nonbasal energy expenditure (TEE-RMR) divided by body weight (MJ/kg/ d) $(p<.01)$. For females, $r=-.83$; for males, $r=-.55$. Adapted from Schulz, and Schoeller (1994).

Although the data were a compilation of very different groups, such as Pima Indians, athletes during an intense cycling race, or healthy individuals in developing countries, the absence of overweight individuals above the level of around $0.1 \mathrm{MJ} / \mathrm{kg} / \mathrm{d}$ was remarkable. This gives new support for the early hypothesis of Jean Mayer et al. (1956) that energy intake matches needs above a certain threshold of daily physical activity. Below this hypothetical level, the human body is unable to match energy output at relatively higher levels of food intake. The resultant weight gain forces increased energy expenditure by increasing body mass and, therefore, both resting and nonresting metabolic rate, until the subject comes back into energy balance at an increased weight and fatness.

Based on this arbitrary threshold of $0.1 \mathrm{MJ} / \mathrm{kg} / \mathrm{d}$, one can calculate the level of activity needed to meet these criteria. For example, an active woman (35 years) who is $65 \mathrm{~kg}$ and $1.65 \mathrm{~m}, \mathrm{RMR}$ is $1330 \mathrm{kcal} / \mathrm{d}$. Nonresting energy expenditure based on this threshold is around 1500 $\mathrm{kcal}$. Assuming that diet-induced thermogenesis is about $10 \%$ of total energy expenditure $(285 \mathrm{kcal})$, the net energy expenditure for physical activity is $1215 \mathrm{kcal}$. This active woman probably has an average aerobic fitness of about $45 \mathrm{ml} \mathrm{O} 2 / \mathrm{kg} / \mathrm{min}$. To spend $1215 \mathrm{kcal}$ at a moderate level of exercise (50\% VO ${ }^{2}$ max) will take her about 170 minutes-almost 3 hours. Even assuming that in a normal day approximately 2 hours of physical activity (standing, walking, etc., at 25\% VO2max) are spent at a low level at an energy cost of $435 \mathrm{kcal}$, the remaining nonresting energy expenditure $(780 \mathrm{kcal})$ will require another 105 minutes at a moderate intensity level. This is a highly unrealistic amount of daily physical activity to perform to maintain a very small risk for becoming obese. It illustrates that to prevent obesity, the recommended active lifestyle is not a "once a week" activity.

\section{Nutrient Balance and the Predisposition to Become Obese}

The fact that body fat stores increase only when energy intake exceeds expenditure obviously remains the first condition for gaining weight. However, a recent demonstration of a close relationship between energy balance and substrate balance imposes a second condition to reach a state of energy balance. This notion of substrate balance requires specific information about macronutrients regarding intake, availability for oxidation and storage, and, particularly, the role of physical activity in this process. In fact, although each macronutrient has its peculiarities, the main interest here is the balance of lipids.

At the opposite of what is observed for carbohydrate and protein is the less well developed capacity to adapt fat oxidation to fat intake (Flatt 1988). This is perhaps a consequence of the well developed ability to store excess fat in adipose tissue without much biochemical processing. In contrast, glycogen stores in muscle and liver are very limited, which forces the body to keep carbohydrate oxidation in line with food intake, and vice versa. The inability of lipid oxidation to respond to short term fluctuation in lipid intake is not unlimited. Recent studies in respiration chambers have shown that with increasing percentage of energy from fat, fat oxidation will increase (Karst et al. 1995) On a long term basis, excess intake of fat or impaired fat oxidation leads to a substantial change in the composition of the fuel mix oxidized, which itself contributes to the achievement of a new plateau of weight with a higher percentage of body fat. Schulz et al. (1992) calculated that a weight gain or loss of $10 \mathrm{~kg}$ of fat mass was accompanied by a mean change in lipid oxidation of about $20 \mathrm{~g} /$ day.

In this context, the individual variation in capacity to use fat as an energy substrate may play a crucial role in the regulation of energy balance. A number of studies have now indicated that fat oxidation is impaired in obese or postobese compared with lean individuals. In the study of Lean and James (1988), the postobese had at energy balance a lipid oxidation rate of $2.6 \mathrm{~g} / \mathrm{kg}$ fat-free mass per day compared with the 3.1 and $3.0 \mathrm{~g} / \mathrm{kg}$ fat-free mass in 
the lean and obese group, respectively. It is important to emphasize that the relative lipid oxidation was comparable in lean and obese subjects. This illustrates again the generally accepted idea that obesity per se may potentially correct a deficit in lipid oxidation, with the consequence that a higher lipid and energy balance can be achieved under high fat diet conditions.

We (Blaak et al. 1994) and others (Astrup ef al. 1992) have shown that in obese or postobese subjects, lipid oxidation is impaired. Recently this observation was confirmed by Colberg et al. (1995). They found in women with visceral obesity a rednced postabsorptive lipid utilization in leg muscle. Therefore, it is likely that under high fat diet conditions, as is frequently seen in industrialized countries, individuals with a genetic predisposition to have a low ability to increase lipid oxidation will reach a steady state body weight at a considerably higher fat mass level.

\section{Exercise and Nutrient Balance}

Of importance in explaining the phenomenon of reduced capacity to oxidize lipid is the observation of Wade et al. (1990) showing that obese men at a workload of $100 \mathrm{~W}$ oxidized less lipicl compared with lean men. In the same group of individuals, Wade et al. found that the proportion of slow twitch muscle fibers was inversely related to fatness.

Slow twitch (type 1) muscle fibers, well endowed with mitochondria, usually work in an oxidating way and preferentially use fatty acids as an important fuel source. In contrast fast twitch (type 2) fibers, particularly those that are not adapted to regular exercise, have fewer mitochondria and will readily use the glycolytic pathway for energy supply.

This relationship between muscle fiber type and weight gain has focused attention on the muscle compartment is a possible target organ with a defective thermogenic response. Astrup et al. (1992) demonstrated that skeletal muscle is the major site of induced thermogenesis in response to carbohydrate feeding via the sympathetic nervous system. The beta-2-adrenergic receptors are especially important in muscle. We found that the beta adrenergic stimulation of muscle metabolism explains nearly $100 \%$ of the whole body increase in energy metabolism after stimulation (Blaak et al. 1994).

In a controlled 2-week study of the effect of the beta adrenergic blocker propanolol, Acheson et al. (1988) showed in a very elegant way a significant decrease in $24-$ hour lipid oxidation $(21 \mathrm{~g} / \mathrm{d})$ with a concomitant increase in carbohydrate oxidation $(28 \mathrm{~g} / \mathrm{d})$ and a nonsignificant decrease in energy expenditure of the $64 \mathrm{kcal} / \mathrm{d}$. This shows the importance of the sympathetic nervous system and the variation in its activity in the regulation of substrate and energy balance.

This sympathetic-adrenergic responsiveness and the aforementioned muscle morphology are both effectively influenced by exercise training. Longitudinal and cross- sectional studies in animals and humans have demonstrated that dramatic changes can occur in skeletal muscle in response to training (Saltin and Gollnick 1983). For instance, several studies have demonstrated a large increase in mitochondrial protein of skeletal muscle during endurance exercise. This increases the capacity of several metabolic pathways, including beta oxidation. The magnitude of this increased oxidative potential varies as a function of the duration and intensity of the training program. As a consequence, a shift can be observed to a greater use of lipids at the same relative intensity of exercise in trained versus untrained subjects. Furthermore, in relation to the sympathetic adrenergic control, Richter et al. (1984) showed that endurance training augments the stimulatory effect of epinephrine on energy metabolism in skeletal muscle.

It is obvious that additional studies are needed to determine whether a reasonable level of daily physical activity changes the metabolic capacity of the muscle cell and stimulates the sympathetic nervous system in such a way that a positive effect on lipid and energy balance can be expected.

\section{Conclusions}

The evidence reviewed in this paper shows that based on the precise doubly labeled water method, nonbasal energy expenditure - and more specifically exercise-induced energy expenditure - is an important component in the regulation of weight balance. In situations of over- or underfeeding, spontaneous physical activities are adapted. Unknown so far is the regulatory mechanism. It became clear that the muscle compartment plays a vital role in this mechanism. Energy balance cannot be reached without lipid balance. Since lipid balance is not very well regulated in the short term, a high fat intake will induce lipid imbalance. To compensate, fat stores will be increased to reequilibrate oxidation with lipid intake. The muscle possibly plays a key role in the regulation of lipid oxidation. Evidence is available that in the obese and postobese, the ability to oxidize lipids is impaired. So far, it is unknown whether this has a genetic component. In addition, physical inactivity can lead to a biochemical alteration in the muscle cell, leading to a shift toward carbohydrate oxidation.

Furthermore, recent observations suggest that betaadrenergic receptors in particular play a crucial role in the thermogenic function of the muscle cell. Therefore, it is relevant to suggest that further research should be focused on the effects of physical activity on the sympathetic nervous system in relation to lipid oxidation in the muscle compartment.

\section{References}

Acheson KJ, Ravussin E, Schoeller DA, et al (1988) Two-week stimulation or blockade of the sympathetic nervous system in man: influence on body weight, body composition and twenty-four energy expenditure. Metabolism 37:91-98 
Astrup A, Buemann B, Christensen NJ, et al (1992) Failure of post-obese subjects to increase ratio of 24-h fat-to-carbohydrate oxidation in response to a high fat diet. Int $\mathbf{J}$ Obes 16(suppl. 1):13-18

Astrup A, Bülow J, Madsen J, et al (1985) Contribution of BAT and skeletal muscle to thermogenesis induced by ephedrine in man. Am J Physiol 248:E507-514

Blaak EE, Van Baak, MA, Kemerink MTW, et al (1994) Betaadrenergic stimulation of energy expenditure and forearm muscle metabolism in lean and obese men. Am J Physiol 267:E306-E315

Colberg SR, Simoneau JA, Thaele FL, Kelly DE (1995) Skeletal muscle utilization of free fatty acids in women with visceral obesity. J Clin Invest 95:1846-1853

Flatt JP (1988) Importance of nutrient balance in body weight regulation. Diabetes Metab Rev 6:571-581

Karst H, Gerstmann U, Barth CA (1995) Fat oxidation and fat balance at varying fat and energy intake [abstract]. FASEB J 9:A280

Keys A, Brozek J, Henzel A, et al (1950). The biology of human starvation, vol 1. University of Minnesota Press, Minneapolis, $\mathrm{MN}$

Lean MEJ, James WPT (1988) Metabolic effects of iso-energetic nutrient exchange over 24 hours in relation to obesity in women. Int J Obes 12:15-27

Leibel RL, Rosenbaum M, Hirsch J (1995) Changes in energy expenditure resulting from altered body weight. $N$ Engl J Med 332:621-628

Mayer J, Roy P, Mitra KP (1956) Relation between caloric intake, body weight and physical work: studies in an industrial male population in West Bengal. Am J Clin Nutr 4:164-175

Poehlman ET (1989) A review: exercise and its influence on resting energy metabolism in man. Med Sci Sports Exerc 21:515525

Poehlman ET, Melby Cl, Badytak SF (1988) Resting metabolic rate and post-prandial thermogenesis in highly trained and untrained subjects. Am J Clin Nutr 47:793-798

Ravussin E, Lillioja A, Knowler WC, et al (1988) Reduced rate of energy expenditure as a risk factor for body weight gain. $\mathrm{N}$ Engl J Med 318:467-472

Richter EA, Christensen NJ, Ploug T, et al (1984) Endurance training augments the stimulatory effect of epinephrine on oxygen consumption in perfused skeletal muscle. Acta Physiol
Scand 120:613-615

Saltin B, Gollnick S (1983) Skeletal muscle adaptability; significance for metabolism and performance. In Peack LD, Adrian RH, Geiger SR (eds), Handbook of physiology: skeletal muscle. William and Wilkens, Baltimore, MD, pp 555631

Saris WHM (1986) Habitual physical activity in children: methodology and findings in health and disease. Med Sci Sports Exerc 18:253-263

Saris WHM, Cramwinckel AB, Elvers JWH, et al (1983) How inactive are obese boys [abstract]. 4th International Congress on Obesity, New York, NY, p 41

Saris WHM, Elvers JWH, Van ' $t$ Hof MA, Binkhorst RA (1986) Changes in physical activity of children aged 6 to 12 years. In Rutenfranz J, Mocellin R, Klimt F (eds), Children and exercise XII. Human Kinetics Publ., Champaign, IL, pp 121130

Schulz LO, Schoeller DA (1994) A compilation of total daily energy expenditures and body weight in healthy adults. Am J Clin Nutr 60:676-681

Schutz Y, Tremblay A, Weinsier RI, et al (1992) Role of fat oxidation in the long-term stabilization of body weight in obese women. Am J Clin Nutr 55:670-674

Tremblay A, Fontaine E, Poehlman ET, et al (1986) The effect of exercise-training on resting metabolic rate in lean and moderate obese individuals. Int $J$ Obes 10:511-517

Tremblay A, Nadenau A, Fournier G, et al (1988) Effect of a three days interruption of exercise training on RMR and GIT in trained individuals. Int J Obes 12:103-168

Wade AJ, Marbut MM, Round JM (1990) Muscle fiber type and aetiology of obesity. Lancet 335:805-808

Waxman M, Stunkard AJ (1980) Caloric intake and expenditure of obese boys. I Pediatr 96:187-193

Weigle DS, Brunzell JD (1990) Assessment of energy expenditure in ambulatory reduced-obese subjects by the techniques of weight stabilization and exogenous weight replacement. Int J Obes 14(suppl 1):69-77

Weinsier RL, Bracco D, Schutz Y (1993) Predicted effects of small decreases in energy expenditure on weight gain in adule women. Int J Obes 17:693-700

Westerterp KR, Meyer GAL, Saris WHM, et al (1991) Physical activity and sleeping metabolic rate. Med Sci Sports Exerc 23:166-170 